\title{
Technological Innovation, Ethics and Legislation as Factors for Quality of Life
}

\author{
Aline Rodrigues Sacomano, Oduvaldo Vendrametto, \\ and Pedro Luiz de Oliveira Costa Neto \\ Paulista University - UNIP, Graduate Program in Production Engineering, \\ Dr. Bacelar St. 1212, 04026-002, São Paulo - SP, Brazil \\ \{aline.sacomano, oduvaldov, politeleia\}@uol.com.br
}

\begin{abstract}
The aim of this article is to show that technological innovation, ethics, and the law contribute to an improvement in the quality of life of society, considering also that the major technological changes are followed by economic, social and institutional transformations, requiring legal supports, economic motivation and appropriate political and institutional conditions to be developed. Besides dealing with the concepts of ethics and technological innovation, are also addressed the laws of innovation and industrial property, since both are directly related to the theme of the paper. Quality of life is also conceptualized according to the World Health Organization, being understood that, to achieve advantages in quality of life of society, ethics must be present in all relations. Technological innovation, that generally boosts the economic growth of the country, should be encouraged and, simultaneously, the laws that enforce the relations in society rules must be adequated and improved according to the needs of the citizens and organizations.
\end{abstract}

Keywords: value aggregation, social responsibility, sustainability, quality of life.

\section{Introduction}

This article deals with concepts that are being increasingly recognized by their importance in the present actuality of humanity and the relations among them.

According to [1], the concepts of ethics, legislation, product and service quality, sustainability and social responsibility are related to the improvement of quality of life of society, as shown in Figure 1.

It is worthy to notice that the concept of ethics was considered outside of the dominion of law, since it extrapolates legal requirements towards legitimate issues.

This article will show that technological innovation is also a factor that can contribute to the improvement of quality of life of society. However, it must be considered that, for a country to be technologically developed, it is necessary that its people have education, work, adequate health care system, properly applied laws, besides ethics and transparency in relationships, not only due to organizations in general, but also from the Government, the rulers and citizens, in all spheres. 


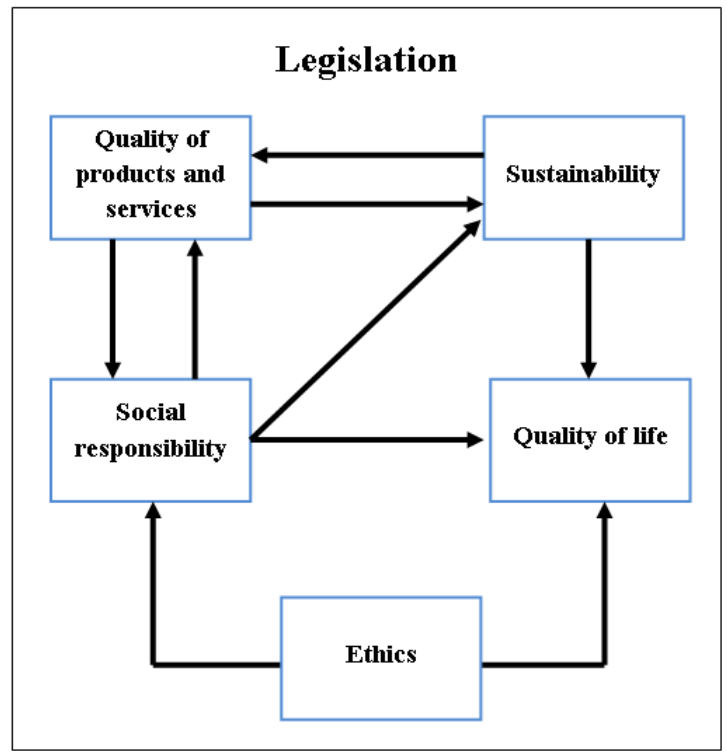

Fig. 1. Relations among concepts. Source: [1]

In addition, technological innovation has also its negative face, as may be seen, in the course of History, through the arise of several machines and equipment with innovations replacing human labor, causing unemployment and serious social problems [2]. It may also be considered the new products and services imposed to population by massive propaganda which become a necessity, frequently forced and of doubtful usefulness.

In fact, according to [3], the reasons for unemployment in Brazil are, among others, the low professional qualification of workers together with technological innovation, what is leading an increasing number of enterprises to change human work for machine work.

[4] considers that the major technological changes are followed by economic, social and institutional transformations, because technology does not spread in the vacuum, requiring legal support, economic motivation and appropriate political and institutional conditions to develop.

The Brazilian industrialization model has not demonstrated a strong capacity for innovation, because Brazil has historically imported most of the technology which uses and spent low effort on research \& development. The actual Brazilian industrialization came only from about 1950, when was basically set up the model of imports substitution, based on the importation of foreign capital and technologies [5].

Even at present, quantitative surveys indicate that the Brazilian system of science and technology has made a small amount of general investment, supported mainly by government initiatives and with little involvement of companies. This system is inefficient compared with other countries like United States, Germany, Japan, France, Canada and South Korea [6]. 
Moreover, the quick development of South Korea deserves to be highlighted since 1967, when this country began an extensive development programe aimed to support its growth by continued increase of competitiveness of the economy and the achievement of an ever-growing share of international trade. South Korea is now in a safe route of enrichment, with all its economic indicators and research performance rising much faster than the Brazilian ones [7].

The Koreans have identified the pillars that sustain a stand-alone development, such as education of qualified basis and the previlege for the training of technicians and engineers, factors that have favored learning technological development through reverse engineering and business management [5].

[8], speaking about the major changes in South Korea, summarizes: "...there was therefore progress in obtaining a business structure less concentrated, more transparent relations and an economic model more responsive to market signals".

Transparent relations, ethics and legislation are factors to achieve a better quality of life of society. Likewise, technological innovation is also a factor for a better quality of life, since it is an essential tool for increasing productivity and competitiveness of organizations, so as to boost the economic development of regions and countries [4]. However, it should be stated that companies need to be prepared to receive the advantages of innovation, otherwise social problems may be increased.

\section{Ethics in Organizations}

According to [9], morality consists of values, principles and norms of behavior of man in society, while ethics is a systematic set of rational knowledge and goals of human moral behavior.

Ethics currently relates with work, politics, life in society and interpersonal relationships, among many other ways in which human behaviour is important [10].

In a pluralistic society like ours, where the tolerance in coexistence in terms of respect for different ways of thinking and behaviour has reached an advanced stage, there is a risk of falling into the temptation of indifference. In general, any way of thinking and behaving is allowed, not necessarily with concerns about this position or correction of the performance. Just check out how currently, by saying: "This is wrong!" or "It is not correct to proceed in this way!", easily one is taxed of moralist, retrograde or other similar expressions. What would be a breakthrough, the healthy pluralism, turns this way to a dangerous relativism, preventing the possibility of serious ethical actions [11].

According to a study carried out by the Ethos Institute of Companies and Social Responsibility, in partnership with the newspaper Economic Value and the enterprise Public Opinion Indicator, 63\% of participants answered that they take in consideration the treatment given by the enterprises to their employees, besides their concern with the environment and business ethics [12]

Based on this, one can increasingly realize that social responsibility and ethics are still going inside of the mind of organizations, a fact that should bring reflection, since it must be the path to sustainability, to business success and to build a more prosperous and just society [13]. 
Ethics, besides being essential for businesses today, is also beneficial to society. In current society, operating in fast-paced and complex environment with increasing instability, organizations are challenged to put ethical issues as essential to survival [14].

Ethics in business is the application of ethics in a concrete domain, with the identification of rules and ethical principles in the economic and commercial context. The related concept of corporate compliance, very discussed in our days, may be defined as the set of procedures adopted by an organization with the aim of enforcing applicable laws, corporate policies, values and ethical standards, including to identify and prevent any violation or misuse that may occur [15].

Companies of today must deal not only with legal risks, but also with the risks related to image and reputation. The reputation of a company is strongly linked to the level of public trust that it enjoys, amid a growing pressure from consumers and society in general by a more ethical stance. Companies that do not cultivate ethical and environmental values are at risk of losing business [15].

\section{Technological Innovation}

Innovation is usually associated with a process of new technologies. According to [16], technological innovation is defined in the PINTEC - Industrial Research in Technological Innovation by the implementation of products (goods or services) or technologically new or coming from substantially improved processes. The implementation of innovation occurs when the product is placed on the market or the process shall be operated by the company. Technological innovation refers to product or process new (or substantially improved) for the company, not necessarily new to the market/sector of activity, and may have been developed by the company or by another company/institution.

Innovation is also the establishment of something new that represents the aggregation of economic value. It may be of product or of process. In fact, product innovation generally come together with technological innovation of the production process, to enable this innovation to be carried out in practice and reach its potential consumers [17].

For marketing, the definition of innovation, or technology-intensive product, relates the concept with the extent of disruption that a new product may result in infrastructure and in the patterns of behavior. About the consumer behavior in relation to innovation, several researchers sought to understand the factors that lead the consumer to embrace or resist to an innovative technology [18].

For [19], the manifestation of the entrepreneur (producer of innovations) responsible for the project (new combinations of production factors) constitutes the fundamental element of economic development.

[20] argues that technological innovations, which lead to economic development, employment, income growth and social inclusion, also depends on the existence of a large numbers of small, medium and large companies permeating the productive sectors and disseminated in all segments of the economy and regions of the country. 
However, in order that technological innovation brings economic results for the country, it must be transmitted to the market and used by consumers or by the production process of goods or services.

The most dynamic and profitable companies in the world are precisely those most innovative that, rather than compete in saturated markets, create their own niches and enjoy temporary monopolies through patents and industrial secret [2]

It is also important that these innovative companies do not forget ethics, social responsibility and sustainable development of the planet, so that society reach the utmostly aimed quality of life.

According to [21], many organizations have achieved a good advantage in sustainability because they always look to the future and plan new environmental technologies. It is what Wal-Mart is doing, since it opened two super experimental stores designed to test dozens of technologies for efficient use of energy that do not harm the environment.

Companies are re-examining their connections with the social values and responsibilities with the planet where we live. As the environmental and social movements mature, companies suffer pressures to assume greater responsibility for environmental and social impacts of their actions. Corporate ethics and social responsibility have become important topics in virtually all areas of business, and few companies can bypass the renovated and demanding environmental movements.

\section{Laws: Technological Innovation and Industrial Property}

The law is a system of rules governing human behaviour [22]. Therefore, it is essential that there are laws well prepared and properly applied, mainly to improve the quality of life of society.

The stimulus to innovation brings to the market more competitive products and services, generates employment, income and development. In this respect, the new legislation aims to regulate the situation of private companies and create a system of tax incentives for their development, starting with hiring researchers and companies without competitive bidding [23].

An innovation law exists in Brazil since 2004, as a new instrument for fostering innovation and scientific and technological research in the productive environment, which seeks mainly to promote and encourage the scientific research and to develop technology excellence, as put in articles 218 and 219 of the Federal Constitution. However, so that the legislation is actualy efficient, it is important to resolve important issues still to be addressed, such us the lack of flexibility in the management of research institutions.

In this way, it is necessary to go beyond the approval and regulation of technological innovation, since it does not end in itself. To overcome these difficulties and achieve their purposes, the implementation of the law of technological innovation will require an effective interaction of government action with the private sector, the scientific and technological community and the workers [24]. For these authors, the law of technological innovation emerges as a relevant institutional instrument to support industrial and technological policies in Brazil. 
Beyond this, Industrial Property legislation also deserves to be considered in the context of this article. It is, of course, very important to incentive and to protect researchers' rights, as a fair compensation for their efforts. It is understood by industrial property rights those resulting from the conceptions of human intelligence that arise and produce novelties in the industrial sphere. In Brazil, these rights are regulated by the law Nr. 9,279/1996 [25]. Intellectual Property makes it possible to transform knowledge, in principle an almost-private asset, into a public asset, being the connecting link between knowledge and the market [26].

The intensity of scientific and technological development; the approach and interpenetration between science and technology (approaching science from the market in a way not previously experienced); the dramatic reduction in time required for technology development and incorporation to the results of the productive process; the reduction of the life cycle of products on the market; high research and development costs and the risks implicit in technological option; the incorporation of innovation as an expansion of competitiveness; and, particularly, the ability of codification of knowledge, all these aspects increase the importance of intellectual property protection as a mechanism to guarantee the rights and investment stimulus [25].

A set of statutes and laws regulates industrial property in its several dimensions and defines the object of legal protection. Industrial property covers a set of activities related to the industrial application of inventions, industrial design, trademarks, geographical indications and designations of origin, unfair competition and information not revealed (business secrets).

However, a detailed analysis of this legislation deserves a specific work by the importance of the subject, because it is true that there are flaws in the process of granting trademarks and industrial records.

The process of patent grant presents itself as a bottleneck. The time difference between the deposit and the grant indicates the lag in the ability in the examination of requests [27].

\section{$5 \quad$ Final Considerations}

Every man wants to improve his physical and mental welfare or, namely, his quality of life. The World Health Organization (WHO) defines quality of life as "the individual's perception of his position in life, context of culture and values system in which he lives and in relation to his goals, expectations, standards and concerns".

The present study sought to demonstrate through the concepts of ethics, technological innovation and some laws, in particular the industrial property and innovation ones, that there is an interconnection between them, and this interface is capable of improving the quality of life of a society.

So, there must be a place, in Figure 1, for technological innovation. The authors still did not arrive to a consensus about the best way to do it, and shall thank for any help from the readers on this issue.

Ethics and transparency must be present in all relations, in the development of technological innovation and in the preparation and application of laws, for an adequate economic growth and social well-being. 
Laws exist to support the entire society. Analyzing the laws of innovation and industrial property, briefly addressed in the text, it is clear that in Brazil they certainly need upgrades, in order to promote the technological development of the country. This is, of course, a challenge to be faced.

\section{References}

1. Sacomano, A.R., Costa Neto, P.L.O.: The importance of the Brazilian legislation for the improvement in the quality and life. In: APMS. International Conference on Advances in Production Management Systems, Rhodes, Greece (2012)

2. Sacomano, A.R., Costa Neto, P.L.O.: Corporate social responsibility in Brazil as an element to sustainability. In: APMS - International Conference on Advances in Production Management Systems, Cernobbio, Italy (2010)

3. Singer, P.: Globalisation and unemployment, diagnoses and alternatives. São Paulo: Context (1999)

4. Tigre, P.B.: Innovation management. Elsevier, Rio de Janeiro (2006)

5. Vendrametto, O.: The technological innovation policies: alignment proposal for development of endogenous production chains. In: Fusco, J.P.(org) Emerging Topics in Industrial Engineering II, Arte e Ciência, São Paulo (2003)

6. Albuquerque, E.M.: National System of Innovation in Brazil: an introductory analysis from available data. Science and Technology. Journal of Political Economy 16(3), 63 (1996)

7. Nicolsky, R.: Industrial technological innovation and sustainable development. Strategic Partnerships Magazine (13) (December 2001)

8. Guimarães, A.Q.: State institutions and development: the Korean model and the interpretation of the Asian crisis. Journal of Sociology and Politics 17(34), 253-269 (2009)

9. Vásquez, A.S.: Ethics, 7th edn. Civilização Brasileira, Rio de Janeiro (1984)

10. Aranha, M.L.A., Martins, M.H.P.: Philosophizing. Introduction to Philosophy. Moderna, São Paulo (2003)

11. Cerquinho, F.: Ethics and quality in companies. Master's dissertation, São Paulo University, Polytechnic School, Department of Production Engineering, São Paulo (1994)

12. Cantero, C.: Purchase with attitude. Modern Consumer (May 21, 2003)

13. Duarte, C.O.S., Torres, J.Q.R.: Corporate Social Responsibility: conceptual and historical dimensions. In: Corporate Social Responsibility: the Contribution of Universities. Ethos Institute, São Paulo (2005)

14. Sarmento, A.C.C.: Business Ethics Codes: an analysis of factors influencing effectiveness. Master's dissertation, Estácio de Sá University. Rio de Janeiro (2008)

15. FNQ - National Foundation for Quality Magazine (2011)

16. Vendrametto, O.: Decisions in Technology. In: Costa Neto, P.L.O. (ed.) Quality and Competence in Decisions. Blucher, São Paulo (2007)

17. Costa Neto, P.L.O., Canuto, S.A.: Administration with Quality. Blucher, São Paulo (2010)

18. Limeira, T.M.V.: E-Marketing on the internet in cases. Saraiva, São Paulo (2003)

19. Schumpeter, J.A.: Theory of economic development: an inquiry into profits, capital, credit, interest and the business cycle. Abril Cultural, São Paulo (1982)

20. Caron, A.: Technological innovation in small and medium-sized enterprises. Faes Business Magazine (8) (2004)

21. Kotler, P., Armstrong, G.: Principles of Marketing. Pearson Prentice Hall, São Paulo (2007) 
22. Kelsen, H.: Pure theory of law. Martins Fontes, São Paulo (1991)

23. Pereira, J.M., Kruglianskas, I.: The innovation law as an instrument of industrial policy and technological support of Brazil. ournal of Business Administration, RAE-electronics (April/July 2005), http: / /www.rae.com. br (access in March 27, 2013)

24. Martins, F.: Course of Commercial Law. Forensics, Rio de Janeiro (2000)

25. Lastres, H.: Information economy of knowledge and learning. In: Lastres, H., Albagli, S. (eds.) Information and Globalization in the Age of Knowledge, Rio de Janeiro (1999)

26. Buainain, A.M., Carvalho, S.M.P.: Intellectual Property on a globalized world. In: Brazil: Ministry of Science and Technology - MCT, pp. 145-153. Strategic Studies Center, Brasília (2000)

27. Buainain, A.M., Carvalho, S.M.P., Paulino, S.R., Yamamura, S.: Intellectual Property and Technological Innovation: some issues for the current debate. In: Oliveira, D.H. (Org.) The Future of Industry: Productive Chains, Brasilia, vol. 1, pp. 11-38 (2005) 